\title{
EVOLUCIÓN DE LA DINÁMICA VEGETAL MEDIANTE UNA SERIE DE IMÁGENES LANDSAT TM (1986-2011): REGIÓN CENTRAL DE CHIHUAHUA, MÉXICO
}

\author{
L.C. ALATORRE ${ }^{*}$, S. MIRAMONTES-BELTRÁN ${ }^{1}$, A.K. GARCÍA-PEÑA ${ }^{1}$, \\ R. DÍAZ-CARAVANTES ${ }^{2}$, L.C. BRAVO ${ }^{1}$
}

\begin{abstract}
${ }^{1}$ División Multidisciplinaria de la Universidad Autónoma de Ciudad Juárez (UACJ) en Cuauhtémoc, Universidad Autónoma de Ciudad Juárez, CP 31579 Cuauhtémoc, Chihuahua, México.

${ }^{2}$ El Colegio de Sonora (COLSON), OPD. Calle Obregón \#54 Col. Centro, C.P. 83000, Hermosillo, Sonora, México.
\end{abstract}

RESUMEN. En este trabajo se ha analizado la evolución temporal y espacial de la dinámica vegetal sobre varias coberturas de suelo en la cuenca de la Laguna Bustillos, Región de Cuauhtémoc, Chihuahua, México. Se ha utilizado una serie temporal de NDVI, correspondiente a los meses de Abril-Marzo (inicio de primavera). La serie fue construida a partir de imágenes Landsat TM para el periodo del 1986-2011. Los resultados muestran un incremento del NDVI para las áreas vegetadas, en mayor grado para la cobertura de coníferas, mientras que los matorrales y pastizales presentaron una tendencia positiva pero con una menor significancia estadística. El incremento de las temperaturas mínimas a inicios de primavera, durante el periodo de estudio, fue el factor más importante para explicar el incremento del NDVI en las áreas vegetadas. Un análisis espacialmente distribuido muestra grandes extensiones sin tendencia del NDVI, que corresponden a áreas con escasa cobertura vegetal (áreas degradadas). Por otra parte, también aparecen áreas con una tendencia negativa (pérdida de vegetación), explicada por la explotación arbórea utilizada para producir leña, que realizan principalmente los ejidos de la región.

Plant cover dynamics through a series of Landsat TM images (1986-2011): Central region of Chihuahua, México

ABSTRACT. In this research we have analyzed the temporal and spatial evolution
of vegetation dynamics on various land covers in the watershed of Laguna Bustillos,
in the region of Cuauhtémoc, Chihuahua, México. It was used a time series of NDVI
for the month of April (early spring). The series was constructed from Landsat TM for
the period 1986-2011. The results show an increase of NDVI for vegetated areas, to a
greater extent for hedging conifers, while grassland and scrub showed a positive trend
but with lower statistical significance. The increase in minimum temperatures in early
spring during the study period was the most important factor to explain the increase
in NDVI in vegetated areas. A spatially distributed analysis shows large areas without
NDVI trend, which correspond to areas with low vegetation cover (degraded areas). 
Moreover, also areas appear with a negative trend (loss of vegetation), that can be explained by the extraction of wood to be used like firewood, mainly carried in the communal land of the region.

Palabras clave: Landsat TM, NDVI, dinámica vegetal, áreas vegetadas, Chihuahua, México.

Key words: Landsat TM, NDVI, vegetation activity, vegetated areas, Chihuahua, México.

Enviado el 1 de noviembre de 2013 Aceptado el 31 de enero de 2014

*Correspondencia: División Multidisciplinaria de la Universidad Autónoma de Ciudad Juárez (UACJ) en Cuauhtémoc, Universidad Autónoma de Ciudad Juárez, CP 31579 Cuauhtémoc, Chihuahua, México. E-mail: luis.alatorre@uacj.mx

\section{Introducción}

La dinámica vegetal tiene un papel muy importante en la evaluación de los procesos ambientales a causa de su estrecha relación entre la biósfera y los parámetros globales, incluyendo: la concentración de $\mathrm{CO}_{2}$ atmosférico (Zeng et al., 1999), la influencia de la vegetación en el ciclo hidrológico a escala local (Beguería et al., 2003), la estructura y diversidad del paisaje (Olsson et al., 2000), y los procesos de erosión y transporte de sedimentos (Alatorre y Beguería, 2009b; Alatorre et al., 2011).

Además de las condiciones climáticas, existen factores regionales y locales que también afectan a la dinámica vegetal. Por ejemplo, las diferencias espaciales en dicha dinámica están relacionadas con las condiciones topográficas (Florinsky y Kuryakova, 1996; Pueyo y Beguería, 2007), el tipo de suelo (Farrar et al., 1994), la gestión humana, uso del suelo (Stohlgren et al., 1998), y procesos geomorfológicos como la erosión del suelo (Alatorre et al., 2011; Alatorre et al., 2013).

Varios estudios han identificado cambios en la dinámica vegetal a escala continental (Slayback et al., 2003; Delbart et al., 2006), regional y local (Andreu et al., 2007; Martínez-Villalta et al., 2008; Alatorre et al., 2011; Vicente-Serrano et al., 2012) en las últimas décadas. La mayoría de los cambios han sido causados por actividad humana, particularmente por la deforestación (Achard et al., 2002; DeFries et al., 2002; Giglio et al., 2006) y los incendios forestales (Riaño et al., 2007), por otra parte, el abandono rural y la consiguiente marginalización de algunas regiones ha contribuido al proceso de recuperación vegetal (Vicente-Serrano et al., 2004; Vicente-Serrano et al., 2006a, b; Lasanta y Vicente-Serrano, 2007; Sluiter y de Jong, 2007; Alatorre et al., 2011; Lasanta y Vicente-Serrano, 2012). Además, diferentes estudios han mostrado como las actuales tendencias climáticas pueden favorecer el incremento en la actividad vegetal sobre distintos ecosistemas del mundo (Myneni et al., 1998; Kawabata et al., 2001; Lucht et al., 2002), o descenso (Maselli, 2004; Sarris et al., 2007; Vicente-Serrano et al., 2012) de la actividad vegetal. Por ejemplo, en la región mediterránea han surgido diversos patrones 
en la dinámica vegetal. En general, el crecimiento vegetal suele verse favorecido por el aumento de la temperatura en zonas donde el agua no es el factor limitante (Andreu et al., 2007; Martínez-Villalta et al., 2008), pero este incremento térmico tiene un efecto contrario en zonas áridas y semiáridas (Vicente-Serrano et al., 2012).

En el noroeste de México son escasas las evaluaciones sistemáticas de la actividad vegetal, aunque existen algunos trabajos basados en la teledetección. Por ejemplo, Salinas-Zavala et al. (2002) estudiaron el efecto macro-regional del fenómeno de El Niño (ENSO) sobre indicadores como el Índice de Vegetación Normalizado (NDVI), y aportaron elementos para entender la variabilidad interanual de procesos como el incremento de la actividad vegetal a escalas geográficas amplias. Autores posteriores como Franklin et al. (2006), Romo (2006), y Bravo y Castellanos (2013) utilizaron el mismo índice para monitorizar el comportamiento de la Producción Primaria Aérea (PPA) en zonas naturales y explotadas por la ganadería, discriminando el efecto de las actividades humanas y los ciclos naturales de la vegetación en esta zona del país.

Los resultados de estos estudios anteriores se restringen a regiones y periodos muy específicos (Centro y Costa de Sonora, en periodos de un año), o al uso de imágenes satelitales (AVHRR) cuya resolución espacial no permite estudios de detalle. Ello hace que se identifiquen lagunas de investigación notables en la región que permitan: i) evaluar los cambios en la cubierta vegetal en las últimas décadas; ii) detectar la tendencia global de la biomasa vegetal; iii) estudiar los cambios de la actividad foliar en regiones forestales; iv) analizar el control que ejercen las variables climáticas (temperaturas y/o precipitación) y los patrones espaciales de la aridez; v) determinar el efecto antropogénico de los usos de suelos; y vi) estudiar las variaciones temporales y espaciales de la dinámica vegetal en áreas degradadas (cárcavas y zonas de riesgo de erosión), donde la vegetación es escasa. En este sentido, los objetivos de este estudio fueron: i) obtener un mapa de coberturas y uso de suelo con las categorías más representativas del área de estudio por medio de una clasificación supervisada; ii) analizar la evolución temporal de la actividad vegetal de las de las coberturas y uso de suelo que se localizan en las sierras y piedemontes que delimitan el área de estudio mediante una serie temporal homogenizada de imágenes Landsat TM (1986-2011); iii) determinar qué variables climáticas ejercen un control sobre la actividad vegetal y definir tendencias temporales estadísticamente significativas; y iv) analizar la distribución espacial que presentan las tendencias temporales de actividad vegetal, como indicador de recuperación o degradación de la cubierta vegetal, y cuantificar los efectos de varios factores topográficos sobre dichas tendencias.

\section{2. Área de estudio}

El área de estudio se localiza en la cuenca de la laguna de Bustillos, entre las coor-

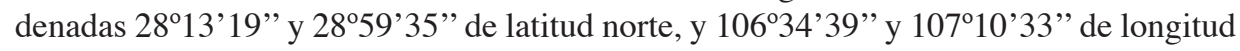
oeste (Fig. 1A), con un área total de $2298 \mathrm{~km}^{2}$. Es una cuenca cerrada de forma irregular por las sierras de Pedernales, San Juan, Salitrera, Chuchupate, Sierra Azul y Rebote, por lo cual la única aportación de agua es la procedente de la lluvia. La cuenca presenta una elevación media de 2000 m s.n.m., y está rodeado al norte, este, oeste y suroeste, por un conjunto de elevaciones que promedian $2400 \mathrm{~m}$, con algunos picos que alcanzan a llegar 
hasta los 2887 m (Fig. 1B). La Comisión Nacional del Agua (CONAGUA, 2010) indica que la climatología del lugar presenta una precipitación media anual de $415.7 \mathrm{~mm}$, con clima semiseco templado y una temperatura media mínima de $14.6^{\circ} \mathrm{C}$ y máxima de $38^{\circ} \mathrm{C}$ a lo largo del año (Fig. 1C).

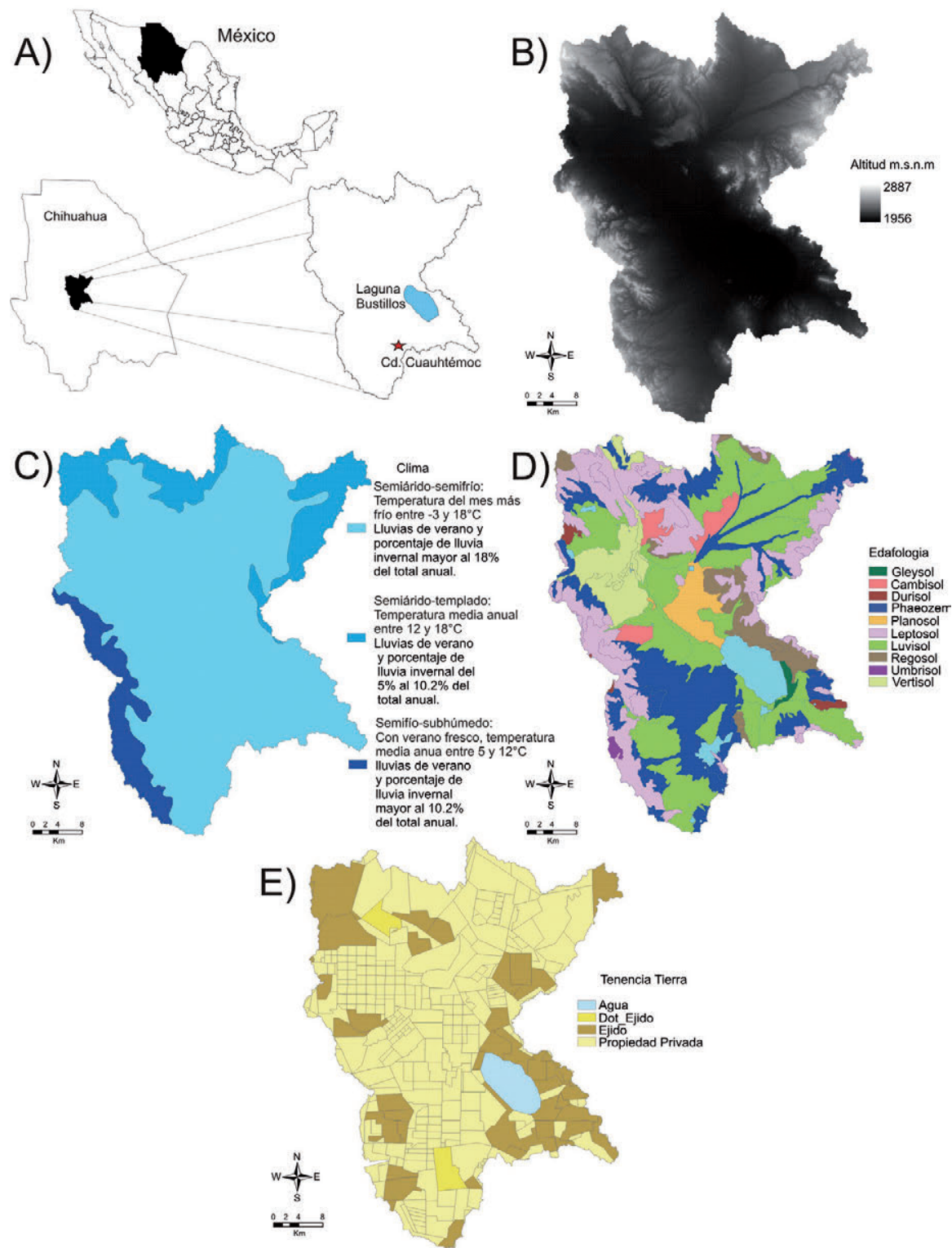

Figura 1. Área de estudio: A) Localización de la Cuenca de la laguna Bustillos, Chihuahua, México; B) Modelo Digital del Terreno (MDT); C) Climas presentes en la región; D) Unidades Edafológicas (INEGI, 2007; Conjunto de Datos Vectorial Edafológico, Escala 1:250000 Serie II); y E) Tenencia de la tierra (Gobierno del Estado de Chihuahua). 
El fondo del valle esta ocupado principalmente por suelos de tipo Phaeozems (Fig. 1D), caracterizados por una marcada acumulación de materia orgánica en la parte superior del suelo, por lo cual son suelos fértiles y soportan una gran variedad de cultivos, así como pastizales. En la región también aparecen Vertisoles, cuya característica principal es la alternancia entre el hinchamiento y la contracción de las arcillas, lo que hace que se vuelvan duros en la estación seca y plásticos en la húmeda, haciendo que el labrado sea muy difícil excepto en los cortos periodos de transición entre ambas estaciones. En general con un buen manejo, son suelos muy productivos. Los Luvisoles, de gran potencialidad para un gran número de cultivos a causa de su moderado estado de alteración y su, generalmente, alto grado de saturación. La unidad de suelos que predominan las sierras y los piedemonte son los Leptosoles. Estos suelos se caracterizan por su baja profundidad (menos de 30 centímetros) y por su alto contenido de grava. Son suelos poco o nada atractivos para su cultivo, presentan una potencialidad muy limitada para cultivos arbóreos o para pastos. Lo mejor es mantenerlos bajo bosque, ya que, su alta susceptibilidad a la erosión hace que sea necesario controlar su uso.

Finalmente la información de tenencia de la tierra muestra que el área esta dominada por la propiedad privada (Fig. 1E), principalmente el fondo del valle con las mejores condiciones para el desarrollo de actividades agropecuarias, y las propiedades de ejidales se localizan en la parte de las sierras y piedemonte, zonas que por sus características fisiográficas no permiten una explotación más intensiva.

\section{Datos y metodología}

\subsection{Selección de la base de datos y preparación de la misma}

Una de las limitaciones que plantean las imágenes de satélite es que se encuentran afectadas por una serie de perturbaciones radiométricas: la iluminación solar y las condiciones atmosféricas, que dificultan su utilización. Este tipo de problemas se suelen solventar en las imágenes de baja resolución espacial y alta frecuencia temporal (p. ej., NOAA-AVHRR) mediante la creación de compuestos multitemporales y filtrados (Gutman et al., 1995). En el caso de las imágenes de alta resolución espacial, como las de los sensores Landsat TM, en las que la frecuencia temporal es baja, resulta necesario llevar a cabo procedimientos de corrección más complejos.

En este trabajo, para obtener un mapa de coberturas y uso de suelo, se ha utilizado una escena Landsat TM (resolución espacial de $30 \mathrm{~m}$ ) tomada el mes de Octubre de 2010, mes del año en el que la disponibilidad resulta mayor por la menor frecuencia de cubierta nubosa, además en esta época del año es cuando la agricultura perenne y de temporal están en su máximo desarrollo ocupando el 100\% del área cultivada, lo cual evita confusiones entre el suelo desnudo y áreas de cultivo, o incluso entre praderas con regadío y pastizales naturales, todas ellas con gran extensión de superficie en el área de estudio. La imagen se corrigió geométricamente mediante puntos de control y el algoritmo desarrollado por Pala y Pons (1996) implementado en el software Miramon, en el que se tiene en cuenta la distorsión topográfica mediante la incorporación de un MDT.

El efecto atmosférico sobre la señal electromagnética ha sido corregido mediante el modelo de transferencia radiativa 6S (Vermote et al., 1997). Posteriormente, se corrigió el efecto que introducen las condiciones de iluminación para compensar las diferencias 
causadas por la irregularidad del terreno, para lo cual se ha utilizado un modelo de reflectividad anisotrópico o no lambertiano, ya que ofrece una mayor robustez que los modelos lambertianos (Riaño et al., 2003).

También se ha construido una serie homogenizada de imágenes Landsat TM para el periodo 1986-2011. La base de datos comprende 18 imágenes, correspondientes al inicio de primavera (Marzo-Abril). El procedimiento de corrección geométrica aplicado a cada una de las imágenes de la serie temporal, es el mismo descrito en la primera parte de este apartado. Para la homogenización de las imágenes de esta serie temporal se ha empleado el software Idrisi Kilimanjaro mediante el módulo ATMOSC y se seleccionó el modelo Cos(t), el cual es una mejora del modelo de Sustracción del Objeto Oscuro (DOS) (Eastman et al. 2004). El modelo Cos(t) propuesto por Chávez (1996), aplica la sustracción del objeto oscuro para el efecto de bruma e incorpora una estimación de la transmitancia ya que esta representa la absorción por parte de los gases atmosféricos y de la dispersión Rayleigh. Este modelo asume que la irradiancia espectral difusa del cielo es 0.0 y que el camino de radiación debido a la bruma es igual al número digital (ND) o brillo de cada banda, sin embargo la transmitancia (T) es calculada con el coseno del ángulo cenital del sol (90 - elevación solar). Los datos que se requieren para este método son: i) fecha y hora de adquisición de la imagen; ii) el ángulo solar y del satélite; iii) los valores de ganancia y sesgo y la longitud de onda media de la banda a corregir. Los valores de ganancias y sesgo son incorporados en las unidades $\mathrm{mW} \mathrm{cm}^{-2} \mathrm{sr}^{-1} \mu \mathrm{m}^{-1}$ (milliWatts por centímetro cuadrado por estereoradian y por micra).

Esta serie temporal de imágenes Landsat TM fue usada para identificar la dinámica vegetal, además de los patrones temporales y espaciales de la misma en las áreas vegetadas localizadas en las sierras y piedemonte que delimitan el área de estudio. La tabla 1 muestra la fecha de cada una de las imágenes empleadas para la serie temporal.

Tabla 1. Datos de las imágenes Landsat 5 TM usadas en el área de estudio para identificar la dinámica vegetal como una función de la actividad vegetal, para el periodo 1986-2011.

\begin{tabular}{|c|c|}
\hline \multicolumn{2}{|c|}{ Primavera } \\
\hline Fecha de Adquisición & Sensor \\
\hline $11 / 05 / 1986$ & Landsat 5 TM \\
\hline $04 / 04 / 1990$ & Landsat 5 TM \\
\hline $01 / 04 / 1992$ & Landsat 5 TM \\
\hline $04 / 03 / 1993$ & Landsat 5 TM \\
\hline $08 / 04 / 1994$ & Landsat 5 TM \\
\hline $02 / 04 / 1995$ & Landsat 5 TM \\
\hline $12 / 03 / 1996$ & Landsat 5 TM \\
\hline $02 / 03 / 1998$ & Landsat 5 TM \\
\hline $21 / 03 / 1999$ & Landsat 5 TM \\
\hline $01 / 05 / 2000$ & Landsat 5 TM \\
\hline $17 / 03 / 2001$ & Landsat 5 TM \\
\hline $01 / 04 / 2003$ & Landsat 5 TM \\
\hline $09 / 03 / 2004$ & Landsat 5 TM \\
\hline $11 / 03 / 2007$ & Landsat 5 TM \\
\hline $13 / 03 / 2008$ & Landsat 5 TM \\
\hline $16 / 03 / 2009$ & Landsat 5 TM \\
\hline $19 / 03 / 2010$ & Landsat 5 TM \\
\hline $07 / 04 / 2011$ & Landsat 5 TM \\
\hline
\end{tabular}




\subsection{Procedimiento de clasificación utilizado}

En este apartado el objetivo es definir áreas de la imagen Landsat TM (Octubre-2010) que representen las categorías temáticas presentes en el área de estudio, con una máxima heterogeneidad espectral. Aunque el objetivo principal de este estudio se centra en el análisis de la dinámica vegetal como una función de la actividad vegetal en las áreas vegetadas, que se localizan en las sierras y piedemonte, para el correcto funcionamiento del algoritmo de clasificación es preciso establecer un conjunto de categorías que representen de forma adecuada la variabilidad de cubiertas presentes en la totalidad del área de estudio. Ello es así porque el algoritmo de máxima verosimilitud (ingl. maximum likelihood) tiene en cuenta no sólo las características medias de la signatura espectral de cada categoría, sino también la covarianza existente entre categorías.

La definición de las categorías temáticas, así como la selección de áreas de entrenamiento para cada categoría, se realizaron con la ayuda de 250 puntos de campo y mediante la fotointerpretación de fotografías aéreas para su verificación. El grado de discriminación entre las categorías, se determinó por medio de la signatura espectral de cada una de las categorías y una matriz de contingencia generada mediante el Software Erdas 8.7 a partir de las bandas del espectro reflectivo. Finalmente se ha incorporado como una banda adicional los valores del NDVI (reescalados a valores de 0 a 1 , donde el 0 corresponde a valores de -1 y 1 a valores de 1 ), esto último ha sido necesario para poder discriminar de una forma más robusta la signatura espectral de cada una de las coberturas y usos de suelo.

Tras comprobar la adecuación de la muestra de entrenamiento se aplicó el método de máxima verosimilitud para la clasificación. Para validar la clasificación resultante se calcularon los estadísticos de sensibilidad y especificidad a partir de una matriz de confusión (Alatorre et al. 2009), con la ayuda de 500 puntos aleatorios independientes los cuales se clasificaron por medio de fotointerpretación de fotografías aéreas para su verificación.

\subsection{Series temporales del NDVI (1986-2011)}

Las series temporales del NDVI fueron obtenidas a partir de la serie homogenizada de imágenes Landsat TM (1986-2011), con el propósito de analizar la dinámica vegetal como una función de la actividad vegetal en las áreas vegetadas, que se localizan en las sierras y piedemonte. El NDVI fue calculado como (Rouse et al., 1974):

$$
N D V I=\frac{\rho_{I R}-\rho_{R}}{\rho_{I R}+\rho_{R}}
$$

Donde $\rho_{\mathrm{IR}}$ es la reflectividad en la región del infrarrojo cercano del espectro electromagnético y $\rho_{\mathrm{R}}$ es la reflectividad en la región del rojo. El NDVI es una medida de la capacidad fotosintética de las plantas (Ruimy et al., 1994) y la resistencia estomática con respecto a la transferencia de vapor de agua (Tucker y Sellers, 1986). Sin embargo, algunos estudios han demostrado una fuerte correlación del NDVI con la fracción de la radiación fotosintéticamente activa, la biomasa de la vegetación, la cubierta verde, y el 
índice de área foliar (p. ej. Tucker, 1979; Tucker et al., 1981; Sellers, 1985). Por lo tanto, altos valores de NDVI son indicativos de una alta actividad vegetal.

Para analizar los efectos del clima sobre la actividad vegetal se obtuvo una base de datos del Servicio Meteorológico Nacional (SMN) de México, particularmente se solicitó al Banco Nacional de Datos Climatológicos que incluye registros históricos de la red climatológica nacional (5000 estaciones), con registros en algunos casos desde fines del siglo pasado hasta la fecha. La información utilizada se obtuvo de la estación Cuauhtémoc, Chihuahua, México (Clave SMN: 8026), la cual contiene datos diarios de precipitación, temperatura máxima/mínima diaria, con datos normalizados desde 1942-2010.

Las series temporales de precipitaciones totales y temperaturas máximas/mínimas medias se calcularon a partir de la serie diaria normalizada, sumando los valores diarios durante el periodo inmediatamente anterior a las fecha de cada imagen. Así, las series climáticas se calcularon para los siguiente periodos previos a la fecha de la imagen: 15 días, 30 días, 3 meses (enero, febrero y marzo para las imágenes de marzo, febrero, marzo y abril, para las imágenes de abril) y 6 meses (octubre a marzo, y noviembre a abril, respectivamente).

Las variables topográficas también fueron analizadas para evaluar sus efectos sobre la actividad vegetal. Para ello se utilizó un MDT de $30 \mathrm{~m}$ de resolución derivado del Continuo Mexicano de Elevaciones (CME), el cual ha sido elaborado por Instituto Nacional de Estadística y Geografía (INEGI) y puesto a disposición de los usuarios para su descarga en <http://www.inegi.org.mx/geo/contenidos/datosrelieve/continental/ continuoelevaciones.aspx $>$. Con el MDT se obtuvo la pendiente $\left(^{\circ}\right)$ y orientación de las laderas (aspecto), algunos estudios han demostrado la importancia de estos factores para explicar las tasas de recuperación de la vegetación (Pueyo y Beguería, 2007). También, se derivó a partir del MDT la disección vertical o potencial para la disección del geocomplejo, en este mapa se ilustran las categorías de los tipos de relieve según la clasificación morfométrica por niveles de disección vertical (Priego et al., 2010), derivadas de un MDT. La disección vertical condiciona varias de las particularidades de la estructura del paisaje, por un lado: i) la distribución de algunos de sus componentes (por ejemplo, la distribución de la temperatura, precipitación, de alguna manera la vegetación, y parcialmente los suelos y otros materiales superficiales); y por otro, ii) condiciona su capacidad de asociación como organización espacio-temporal (Priego et al., 2010).

\subsection{Influencia de las tendencias temporales de los factores climáticos sobre la varia- ción temporal del NDVI (1986-2011)}

La existencia o no de tendencias temporales estadísticamente significativas del NDVI se ha utilizado para detectar los procesos de aumento o disminución de la actividad vegetal. Sin embargo, la actividad vegetal (y por lo tanto el NDVI) se puede ver afectado por una serie de factores naturales, principalmente climáticas, que también experimentan una variación temporal. Por lo tanto, se realizó un análisis de regresión multivariante contra el tiempo (año de adquisición de las imágenes) y un conjunto de factores climáticos, con el fin de aislar las tendencias del NDVI atribuibles única y exclusivamente a la dinámica de la vegetación. 
Como un paso previo se realizó un análisis de correlación para determinar el período de tiempo más apropiado para contruir la serie climatológica, y se encontró que el clima presente en los tres meses anteriores a la fecha de cada una de las imágenes tuvo mayor correlación con el NDVI. Por lo tanto, se ha utilizado las series de tiempo de precipitación acumulada, la temperaturas medias diarias máxima y mínima, durante los tres meses anteriores a la fecha de adquisición de la imagen como covariables en el análisis de regresión.

A medida de que la fecha de adquisición de la imagen no coincide entre los años, lo que podría afectar el NDVI, también se ha incluido como covariable el día juliano de la imagen. Además, para comprobar las tendencias temporales de los valores del NDVI que no fueron explicadas por la variabilidad de los factores climáticos y la fecha de adquisición de las imágenes, también se incorporó el año de adquisición de las imágenes como una covariable. Cabe señalar que, al incluir como covariables algunos de los factores naturales que pueden tener control sobre la dinámica de la actividad vegetal (y por tanto el NDVI), su análisis hace posible determinar con mayor precisión la existencia de tendencias temporales en la serie de tiempo anual del NDVI.

Para determinar las variables que explican significativamente la evolución temporal del NDVI sobre cada cobertura se utilizó un procedimiento de retroceso "stepwise" basado en AIC (Akaike's information criterion statistic), implementado en el software estadístico R (R Development Core Team, 2008), tal y como se aplica la función stepAIC en la biblioteca MASS del paquete R para análisis estadístico (Venables y Ripley, 2002). Esta función solo conserva en su análisis aquellas variables que explican de una manera significativa la evolución temporal del NDVI para las diferentes clases de coberturas de suelo, y las variables que no contribuyan a explicar los valores del NDVI son rechazadas. En análisis de los resultados se basa: i) en la bondad de ajuste y el grado de significancia estadística de las regresiones; ii) la selección de las variables explicativas; y iii) el valor del coeficiente beta (estandarizado) para clasificar las variables en función de su importancia relativa en la explicación del NDVI. La presencia de tendencias temporales sobre los valores observados del NDVI que no pueden atribuirse a factores climáticos o astronómicos (día juliano) corresponderán a procesos de revegetación o degradación, los cuales se correlacionan con la covariable "año" (y signo).

\subsection{El rol de los factores topográficos y la distribución espacial de las tendencias tem- porales del NDVI (1986-2011) sobre las áreas vegetadas}

El análisis descrito en la sección anterior permitió determinar la existencia de las tendencias temporales estadísticamente significativas de los valores medios observados del NDVI en cada una de las coberturas, y la relevancia de los factores climáticos y astronómicos. Sin embargo, no se ofrece una discriminación espacial de las zonas que tienen tendencias positivas o negativas. Así, el siguiente paso fue repetir en análisis multivariante píxel por píxel, usando el mismo conjunto de covariables climáticas y astronómicas (día juliano). Esto hace posible obtener un mapa de las tendencias temporales del NDVI que no son explicadas por las 
covariables y, por tanto, observar las zonas sometidas a procesos de degradación (tendencia negativa) o recuperación (tendencia positiva).

Finalmente, con la ayuda del mapa de la distribución espacial de las tendencias temporales del NDVI sobre el área de estudio, se analizó el grado de control que ejercen las variables topográficas sobre las tendencias: i) pendiente $\left({ }^{\circ}\right)$; ii) orientación de las laderas; y, iii) disección vertical, derivadas de un MDT (Fig. 2).
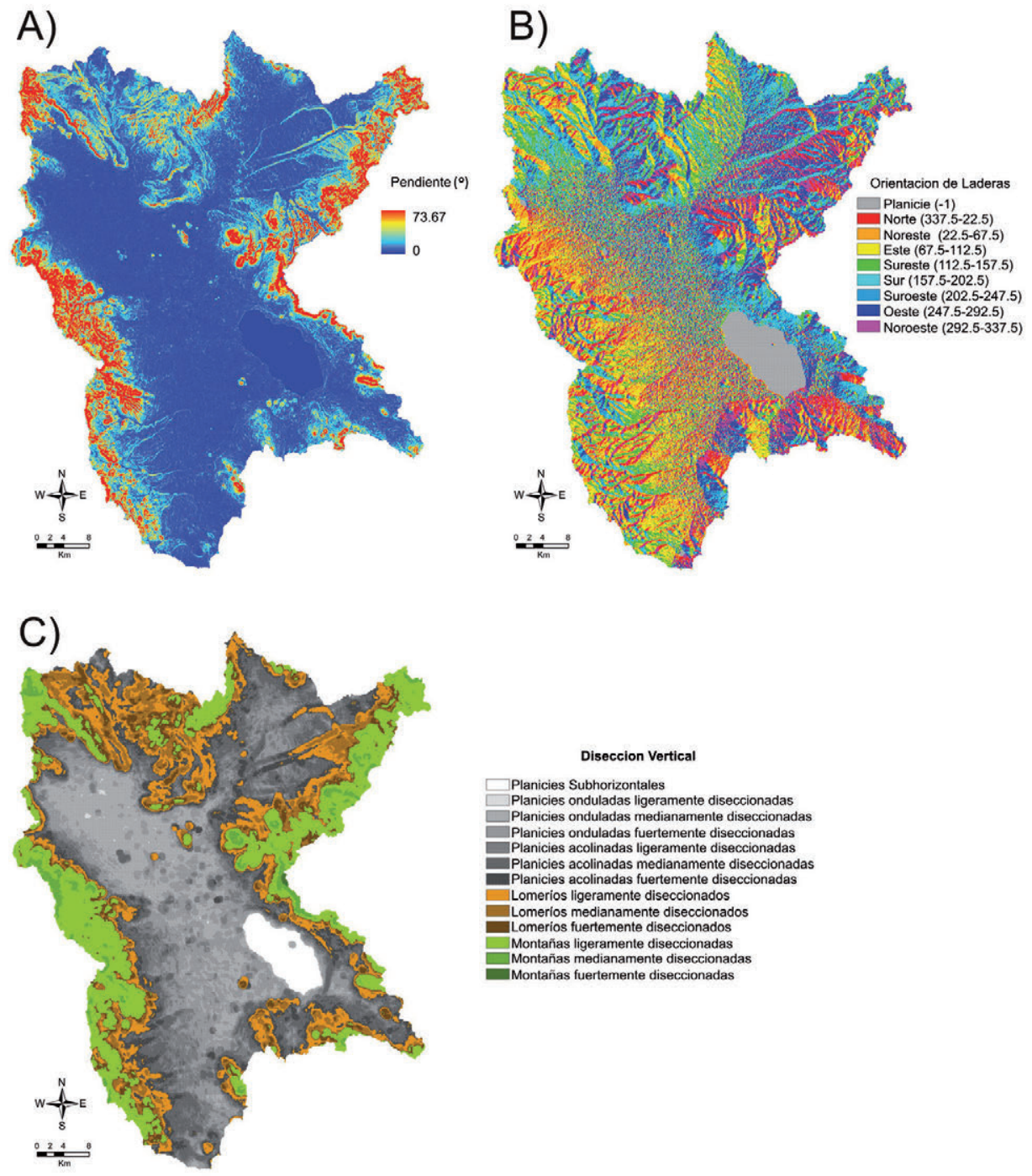

Diseccion Vertical

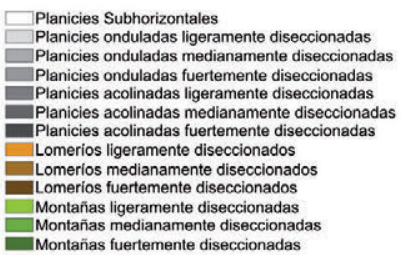

Figura 2. Factores topográficos empleados para determinar dónde se presentan los procesos de recuperación y degradación vegetal: A) pendiente $\left({ }^{\circ}\right) ; B$ ) orientación de laderas (aspecto);

B) disección vertical. 


\section{Resultados y discusión}

\subsection{Selección de las categorías y de las áreas de entrenamiento}

Se consideró que la variabilidad temática del área de estudio resultaba convenientemente representada mediante un conjunto de ocho categorías: asentamientos humanos (urbano y rural), agricultura, huertas de manzano, suelo desnudo, cuerpos de agua, pastizal con matorral disperso, matorral y bosque de coníferas. La selección de áreas de entrenamiento permitió obtener las signaturas espectrales para cada una de las categorías temáticas (Fig. 3). La categoría de suelo desnudo se caracterizó por presentar valores elevados de brillo en todas las bandas y por una mayor variabilidad espectral, y debido a la nula cobertura vegetal los valores del NDVI fueron los más bajos, características que son comunes a las zonas de suelo desnudo (Alatorre y Beguería, 2009). Las categorías de vegetación presentaron una firma espectral típica de este tipo de unidades, con elevados valores de reflectividad en las bandas de la región del infrarrojo (TM-4 y TM-5), y un acusado descenso hacia la región del térmico. En general la información espectral muestra una buena discriminación entre las unidades de vegetación. La inclusión de los valores del NDVI dentro de las firmas espectrales, sin duda ayudó a dar una mayor discriminación entre las categorías de vegetación (Fig. 3).

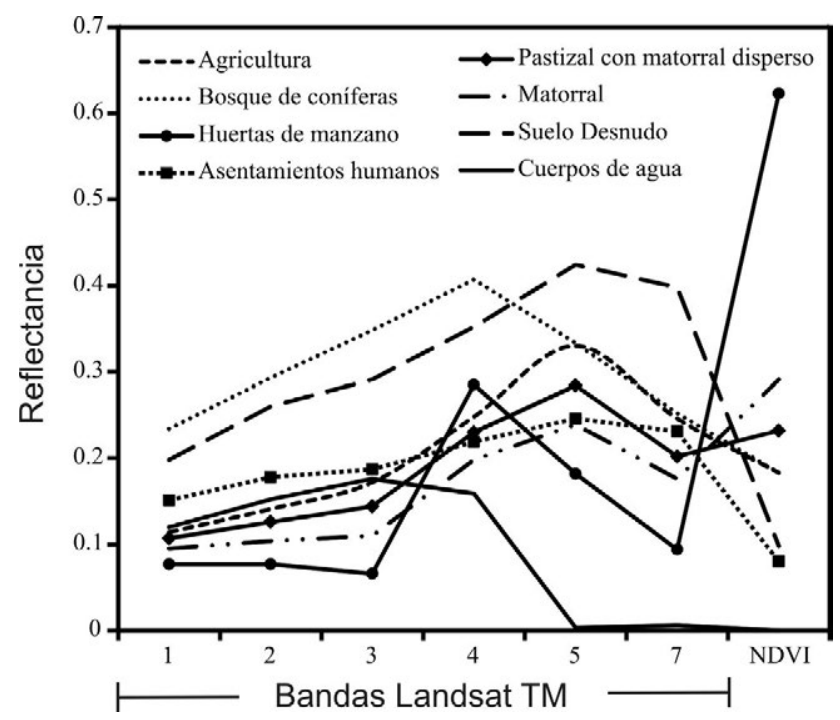

Figura 3. Curvas de brillo (signatura espectral) para cada una de las categorías temáticas en las seis bandas del satélite Landsat TM, más los valores del NDVI (reescalados a valores de 0 a 1 , donde el 0 corresponde a valores de -1 y 1 a valores de 1).

La matriz de contingencia obtenida mediante la aplicación del algoritmo de clasificación de máxima verosimilitud a la muestra de entrenamiento indica que todas las categorías presentan porcentajes de acierto superiores al $80 \%$ (Tabla 2). En el caso del bosque de coníferas, se obtuvo una confusión del $16 \%$ con la categoría de matorral, relacionado principalmente ya que estás unidades se localizan en zonas de transición entre ambas categorías. En primera instancia, este resultado indica que la clasificación resultante sería muy consistente. 


\begin{tabular}{|c|c|c|c|c|c|c|c|c|}
\hline & & & & 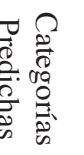 & & & & \\
\hline 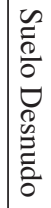 & 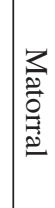 & 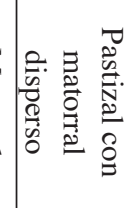 & 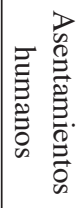 & 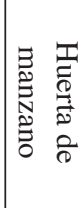 & 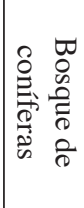 & 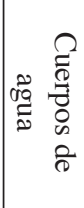 & . & 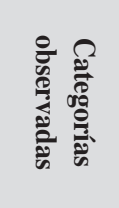 \\
\hline $\begin{array}{l}\circ \\
\text { in } \\
\text { N }\end{array}$ & 용 & $\stackrel{\circ}{\circ}$ & $\begin{array}{l}\circ \\
\dot{8} \\
+\end{array}$ & $\dot{8}$ & $\stackrel{0}{8}$ & 용 & $\begin{array}{l}0 \\
\dot{b} \\
+\infty\end{array}$ & 㿣. \\
\hline 웅 & $\dot{8}$ & $\stackrel{8}{8}$ & 옹 & $\stackrel{8}{8}$ & $\stackrel{8}{8}$ & $\begin{array}{l}0 \\
\text { i̊ } \\
\infty\end{array}$ & $\begin{array}{l}0 \\
\dot{8}\end{array}$ & 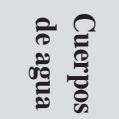 \\
\hline 웅 & $\stackrel{\circ}{\circ}$ & $\stackrel{\circ}{8}$ & $\stackrel{8}{8}$ & 용 & $\begin{array}{l}0 \\
\infty \\
w \\
w\end{array}$ & ஜ & 영 & 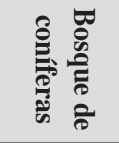 \\
\hline 영 & $\dot{8}$ & $\stackrel{\circ}{8}$ & $\dot{8}$ & 용 & $\stackrel{\circ}{8}$ & ஜீ & 용 & 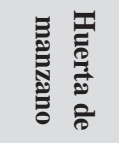 \\
\hline 용 & $\dot{8}$ & $\dot{8}$ & $\begin{array}{l}0 \\
\text { రి } \\
\text { w }\end{array}$ & ஜ & $\stackrel{0}{8}$ & ஜ & : & 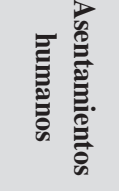 \\
\hline 용 & $\stackrel{\circ}{\circ}$ & $\begin{array}{l}0 \\
\infty \\
\text { N్ర }\end{array}$ & $\stackrel{\circ}{8}$ & 용 & $\dot{8}$ & 용 & $\stackrel{0}{\circ}$ & 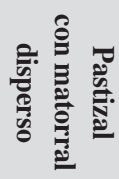 \\
\hline 용 & $\begin{array}{l}\stackrel{一}{\infty} \\
\infty \\
\dot{\omega}\end{array}$ & 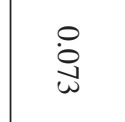 & : & : & 웅 & : & $\stackrel{0}{8}$ & 运 \\
\hline $\begin{array}{l}0 \\
\dot{\circ} \\
\propto\end{array}$ & $\dot{8}$ & ஜ & $\stackrel{\circ}{8}$ & ஜ & 용 & 용 & $\begin{array}{l}\stackrel{0}{0} \\
\dot{\omega}\end{array}$ & 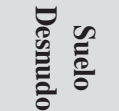 \\
\hline $\begin{array}{l}\infty \\
\ddot{d}\end{array}$ & $\begin{array}{l}\vec{b} \\
\infty \\
ن\end{array}$ & $\frac{\theta}{8}$ & $\begin{array}{c}\tilde{u} \\
\tilde{u}\end{array}$ & 壱 & 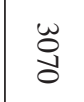 & $\begin{array}{l}\text { No } \\
\mathbb{Z} \\
\text { D }\end{array}$ & 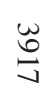 & 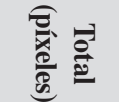 \\
\hline
\end{tabular}




\subsection{Clasificación temática de la imagen}

Una vez validada la separabilidad espectral entre las distintas unidades temáticas del área de estudio, se procedió a aplicar el método de clasificación de máxima verosimilitud para obtener el mapa de coberturas y uso de suelo (Fig. 4). La validación de este mapa mediante una muestra aleatoria independiente arrojo valores de fiabilidad global de $87.64 \%$ (Tabla 3). La mayor confusión se dio en la categoría de huertas de manzano y cuerpos de agua, con un error de comisión de $10.53 \%$ y $0.00 \%$, y un error de omisión de $22.73 \%$ y $23.80 \%$, respectivamente. La categoría de bosque de coníferas fue la que mejor se discriminó del resto de las unidades, con tan solo un error de comisión de $2.7 \%$.

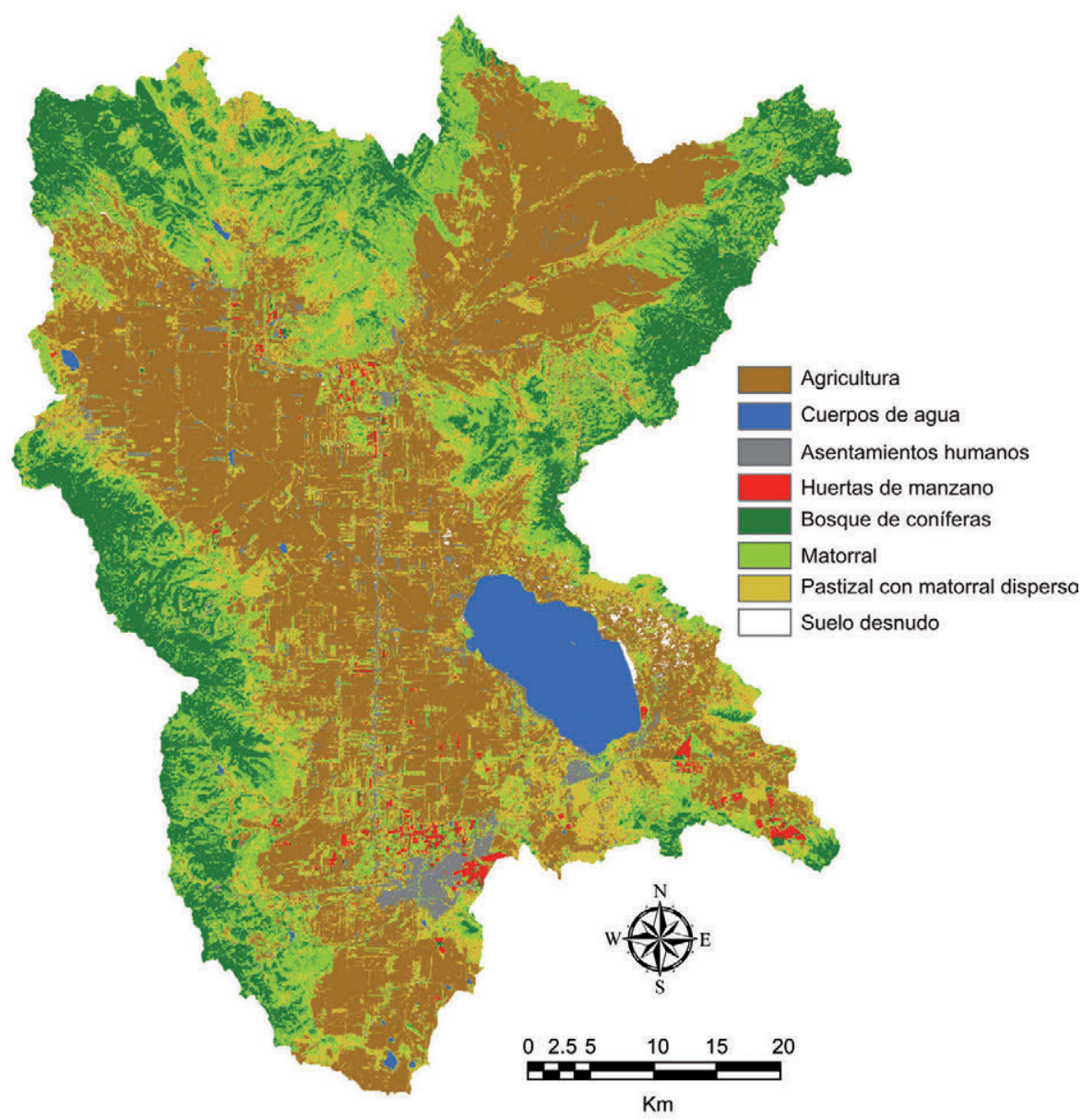

Figura 4. Mapa de cubiertas y usos de suelo obtenido mediante el procedimiento de clasificación supervisada por el método máxima verosimilitud. 


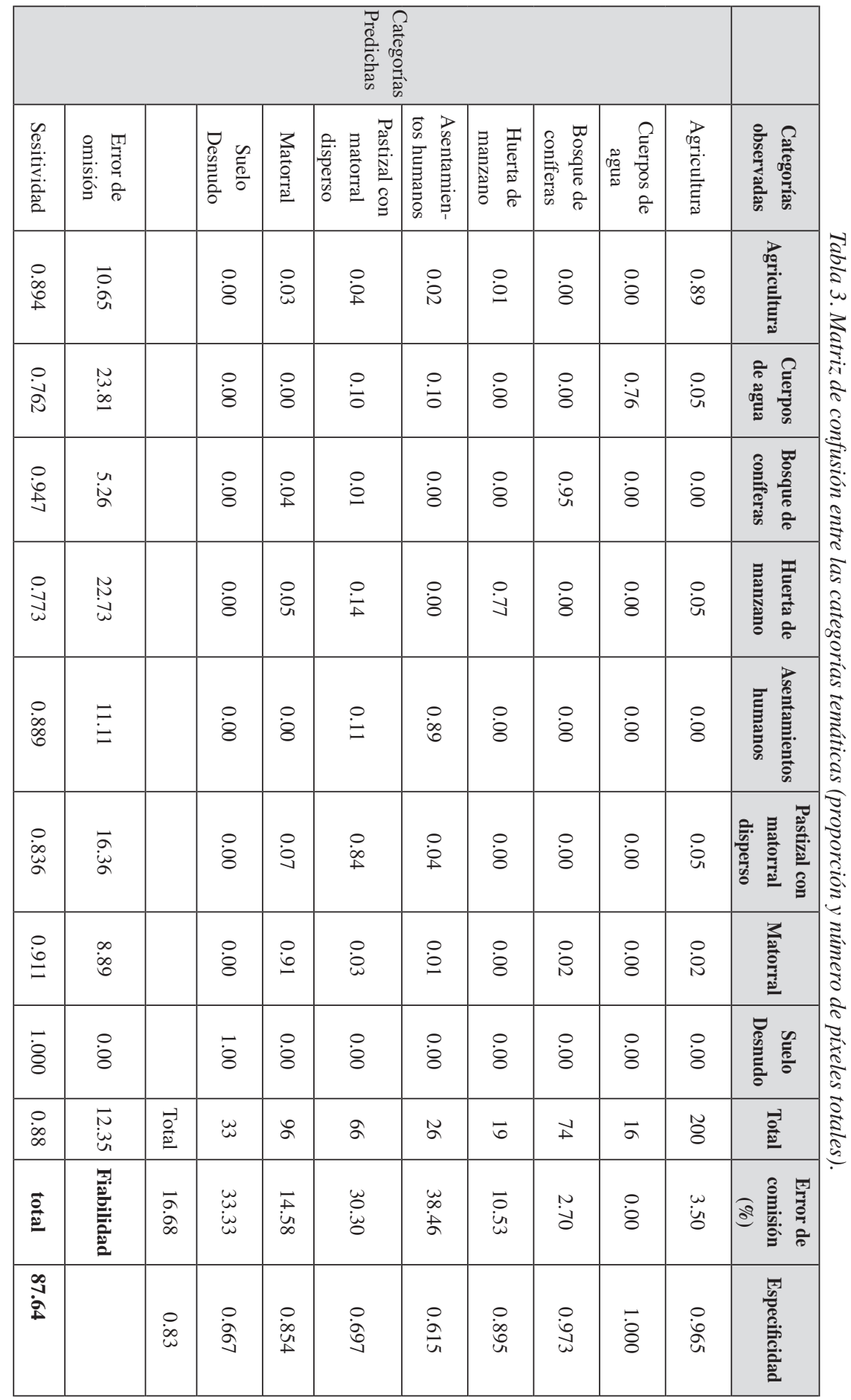


La distribución espacial del área ocupada por cada categoría es: asentamientos humanos (urbano y rural) $109.49 \mathrm{~km}^{2}$, agricultura $1295.32 \mathrm{~km}^{2}$, huertas de manzano $29.21 \mathrm{~km}^{2}$, suelo desnudo $12.16 \mathrm{~km}^{2}$, cuerpos de agua $115.26 \mathrm{~km}^{2}$, pastizal con matorral disperso $538.03 \mathrm{~km}^{2}$, matorral $676.67 \mathrm{~km}^{2}$, bosque de coníferas $512.49 \mathrm{~km}^{2}$. Se observa que las áreas ocupadas por las categorías de asentamientos humanos, agrícolas y huertas de manzano, se localizan en el fondo valle de la cuenca, donde los suelos y topografía son más aptos para las actividades humanas (ver la sección del área de estudio). La categoría suelo desnudo se localizan principalmente en las zonas de transición entre el valle y las sierras, particularmente en los piedemonte, donde los procesos erosivos intensos han dado lugar a formaciones continuas de cárcavas. El término cárcavas es usado para describir áreas de depósitos o rocas pobremente consolidadas e intensamente afectadas por procesos de erosión superficial, caracterizadas por una elevada densidad de drenaje y la rápida evolución de gullies, rills y movimientos superficiales (Gallart et al., 2002). Las cárcavas se desarrollan dentro de una amplia gama de ambientes climáticos, particularmente en ambientes semiáridos y, menor grado, en regiones húmedas y subhúmedas (Bryan y Yair, 1982; Campbell, 1989; Regüés, 1995; Regüés et al., 1995; Pardini, 1996; Torri y Rodolfi, 2000). Casi siempre, las cárcavas están asociadas a una erosión acelerada y, por tanto, a paisajes inestables (Morgan, 1997), por lo que su fijación o la limitación de su ampliación espacial revisten un notable interés aplicado. La distribución espacial de las categorías de vegetación, pastizal con matorral disperso, matorral y bosque de coníferas, sugiere que existe una transición progresiva desde los piedemonte hasta las zonas más altas de las sierras que circundan la cuenca de la Laguna Bustillos (Fig. 4).

\subsection{Influencia del clima sobre las tendencias temporales de NDVI (1986-2011)}

Las series temporales de los valores medios de NDVI mostraron una clara diferencia entre las distintas coberturas y uso de suelo, donde la categoría de bosque de coníferas presentó los valores medios más altos, para seguir de una forma progresiva descendente con las categorías de matorral, pastizal con matorral disperso, y finalmente la categoría de suelo desnudo con los valores medios más bajos (Figs. 5 y 6). La progradación entre los valores medios del NDVI de cada una de las categorías se relaciona con la distribución espacial de las distintas coberturas de suelo (Figs. 4 y 5), donde los valores más bajos se observan en los piedemonte (suelo desnudo y pastizales con matorral disperso), y los valores más altos en las partes más elevadas de las sierras que circundan el área de estudio (bosque de coníferas).

Existen notables diferencias en las tendencias del NDVI (Fig. 6), relacionadas con las distintas categorías de coberturas y uso de suelo. En general, se observa que las áreas vegetadas presentan una tendencia positiva de los valores del NDVI, siendo más evidente para la categoría de bosque de coníferas. En cambio, para la categoría de suelo desnudo se comprueba una tendencia negativa dominante. De acuerdo a esto, las zonas de piedemonte se pueden considerar áreas degradadas (cárcavas y zonas de riesgo de erosión) debido a una escasa e incipiente cobertura vegetal. 


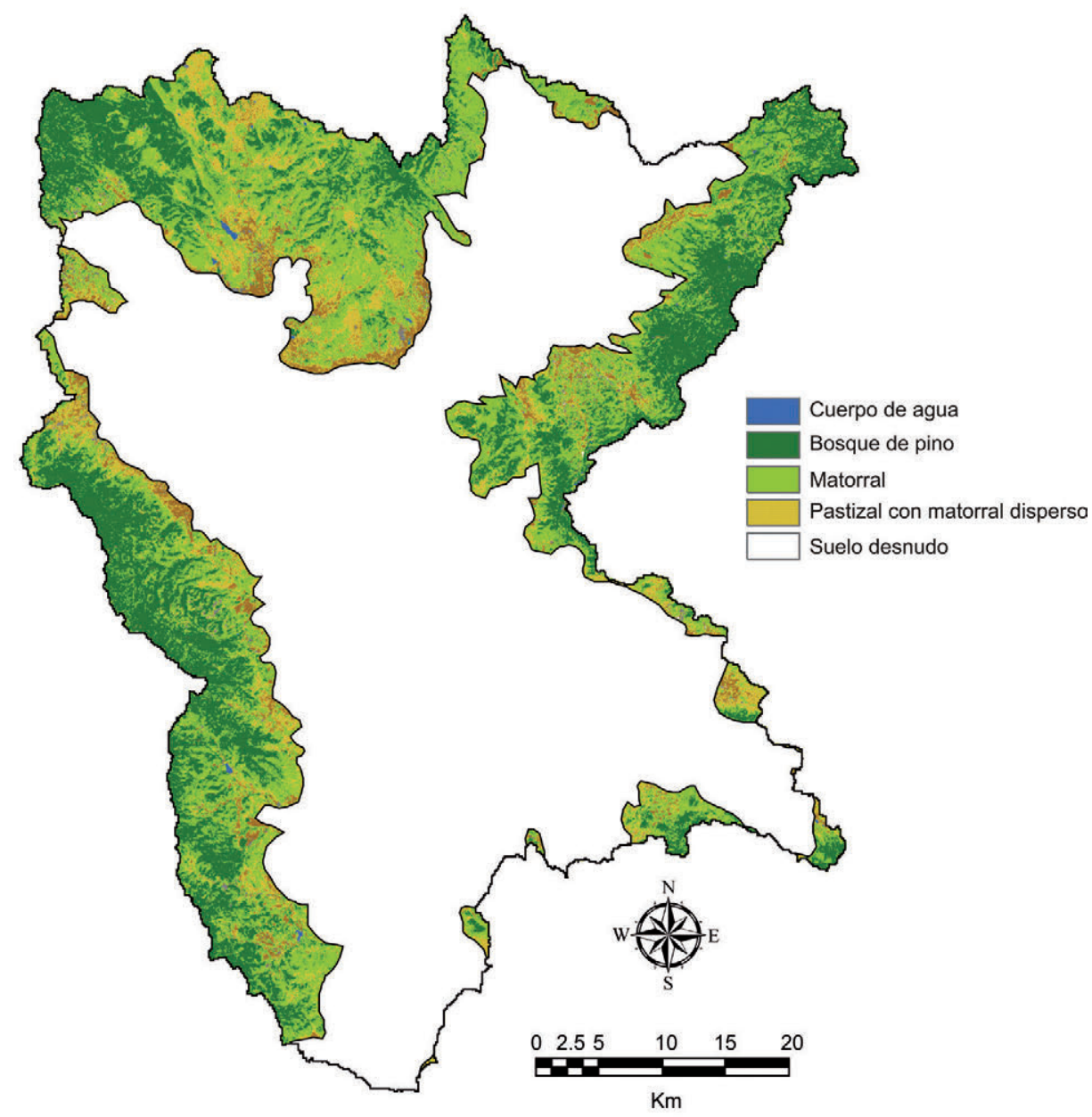

Figura 5. Mapa de las categorías de vegetación localizadas en las sierras y piedemonte para el análisis de la evolución temporal de los valores medios del NDVI en cada una de las categorías. La delimitación de estas áreas se realizó por medio de la disección vertical, es decir, se seleccionaron las áreas que corresponden desde lomeríos ligeramente diseccionados hasta montañas fuertemente diseccionadas, y se eliminaron las categorías de agricultura, huertas de manzana, cuerpos de agua y asentamientos humanos. 
-.. Suelo desnudo $\longleftarrow$ Pastizal con matorral disperso
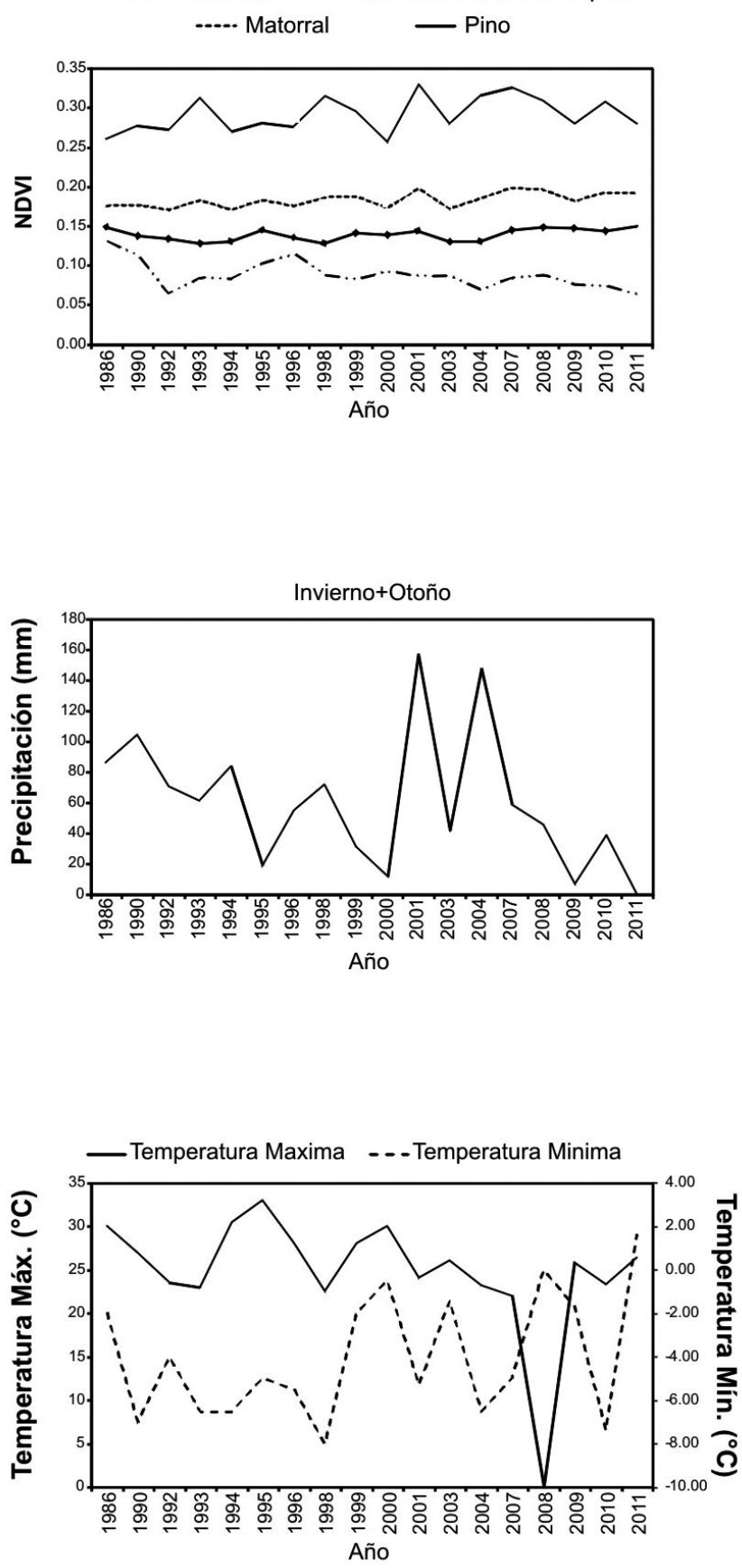

Figura 6. Evolución temporal de los valores medios del NDVI entre las distintas categorías de vegetación y la evolución temporal de las variables climáticas. 
El análisis de regresión multivariante mostró un buen ajuste con los valores observados del NDVI, y alcanzaron una muy buena significancia para todas las coberturas y uso de suelo (Tabla 4). El mejor ajuste del modelo se obtuvo para las categorías de vegetación, particularmente para la categoría de matorral, y el menor ajuste se obtuvo para la categoría de suelo desnudo.

Tabla 4. Análisis de la regresión multivariante para los valores observados del NDVI para cada una de las coberturas y uso de suelo.

\begin{tabular}{|c|c|c|c|c|}
\hline & $\begin{array}{c}\text { Bosque de } \\
\text { coníferas }\end{array}$ & $\begin{array}{c}\text { Pastizal } \\
\text { con } \\
\text { matorral } \\
\text { disperso }\end{array}$ & Matorral & $\begin{array}{c}\text { Suelo } \\
\text { Desnudo }\end{array}$ \\
\hline $\mathrm{R}^{2}$ & 0.94 & 0.82 & 0.98 & 0.69 \\
\hline$p$-Value & $<0.001^{*}$ & $<0.032^{*}$ & $<0.005^{*}$ & $<0.010^{*}$ \\
\hline Residual Standar Error & 0.021 & 0.018 & 0.026 & 0.028 \\
\hline Beta coefficients: & - & - & - & - \\
\hline Precipitation & 0.548 & 0.659 & 0.912 & - \\
\hline T max & 0.840 & 1.830 & 1.690 & - \\
\hline T min & -0.160 & -0.483 & -0.524 & - \\
\hline Julian Day & 0.210 & 0.680 & 0.520 & -0.325 \\
\hline Time (Year) & \multicolumn{5}{l}{} \\
\hline Temporal Trend (Change in NDVI) & +0.00112 & +0.0211 & +0.00368 & -0.00130 \\
\hline Per Year & $+5.24 \%$ & $+6.46 \%$ & $+7.21 \%$ & $-3.56 \%$ \\
\hline Period 1986-2011 &
\end{tabular}

Nota: Las variables excluidas por el procedimiento de retroceso "stepwise" basado en AIC (Akaike's information criterion statistic) aparecen con "- "

*Nivel de significancia estadística $\alpha=0$

Por otra parte, se identifican variables climáticas que controlan de manera significativa las tendencias temporales del NDVI, lo que sugiere que las condiciones climáticas registradas en los últimos 26 años son importantes a la hora de explicar la evolución de la actividad vegetal. La temperatura mínima promedio fue el factor explicativo con mayor peso, como lo demuestran los valores de los coeficientes beta (estandarizado) (Tabla 4). El efecto de la temperatura mínima fue positivo en todos los casos, reflejando la importancia temporal de un clima más cálido a finales de invierno e inicios de primavera para iniciar el periodo de crecimiento de la planta. Esta hipótesis es apoyada por el hecho de que los bosques de coníferas mostraron una influencia mucho menor de las temperaturas mínimas que el registrado por las otras categorías de vegetación, como podría esperarse debido al carácter perenne de las acículas. La temperatura máxima tuvo también un efecto positivo sobre las tendencias del NDVI, aunque en menor grado que la temperatura mínima. De forma contraria, la precipitación acumulada no mostró tener efecto sobre las tendencias temporales del NDVI en las categorías vegetales, lo cual indica que la 
disponibilidad de agua en el área de estudio no ejerce control sobre la actividad vegetal a inicios de primavera. Contrariamente a lo observado para las categorías de vegetación, la categoría de suelo desnudo no mostró estar correlacionada con ninguno de los factores climáticos.

Por otra parte, la fecha de adquisición de la imagen (día Juliano) fue significativo para todas las categorías de vegetación, no así para el suelo desnudo, lo que demuestra la relevancia del estado fenológico de la vegetación en esta época del año y la conveniencia de incluir esta variable en los estudios donde se utiliza el NDVI como una medida de la actividad vegetal durante periodos críticos de crecimiento (Alatorre et al., 2010).

Un vez que la evolución de las tendencias temporales del NDVI fue explicada por los factores climáticos y astronómicos, fue posible determinar la existencia de tendencias en las series temporales del NDVI (variable tiempo, Tabla 4). Se encontraron tendencias temporales positivas del NDVI para las categorías de vegetación, en cambio para la categoría de suelo desnudo se encontró una tendencia negativa. La tendencia más fuerte, correspondió a la categoría de matorral con un valor de $7.21 \%$ de incremento, mientras que para el suelo desnudo fue de $-3.56 \%$, para el periodo de 1986-2011.

Los resultados obtenidos a partir de análisis de la regresión permitieron una interpretación más exhaustiva de los patrones observados en las tendencias temporales del NDVI (Fig. 6). La aparente tendencia a la alza en el NDVI en las categorías de vegetación se pudo explicar por una tendencia similar en las temperaturas mínimas y máximas. Solo en el caso de la categoría de suelo desnudo el análisis de regresión multivariante indicó una tendencia negativa que no es explicada por las variables climáticas, lo que sugiere que en estas áreas existe una disminución en la actividad vegetal por efecto de una degradación o pérdida de la vegetación, posiblemente relacionado con procesos erosivos intensivos.

Estos resultados están muy relacionados con la evolución de la dinámica vegetal observada en otras partes de mundo. En el Pirineo español Occidental, Vicente-Serrano et al. (2004) encontraron un tendencia temporal positiva en los valores del NDVI para bosques y áreas con una buena cobertura vegetal, las cuales se relacionaron con un aumento en la temperatura media anual, los patrones de abandono de la tierra y procesos de revegetación natural (Lasanta et al., 2007; Hill et al., 2008). En el Pirineo Central español, Alatorre et al. (2011) estudiaron la dinámica vegetal en áreas con buena cobertura vegetal, en riesgo de erosión y con erosión activa, sus resultados demostraron que el aumento de la temperatura y la variación de la cubierta de nubes durante el periodo de estudio fueron los factores más importantes en la explicación de la evolución temporal de los valores medios del NDVI (1984-2007) observados en las áreas con buena cobertura vegetal. En el presente estudio también se encontró una tendencia temporal positiva en los valores medios del NDVI, para las categorías de vegetación, y se demostró que las tendencias temporales de las temperaturas mínimas y máximas en los tres meses anteriores a la fecha de adquisición de las imágenes Landsat TM ejercieron una influencia opuesta sobre el NDVI, y que este efecto varió durante el año. 
El hecho de que la precipitación acumulada no tenga ningún efecto significativo sobre la evolución temporal de los valores medios del NDVI podría explicarse por el hecho de que la disponibilidad de agua en el área de estudio no es un factor limitante para el crecimiento de la vegetación, la cual recibe un promedio aproximado de $415.7 \mathrm{~mm}$ año-1 ${ }^{-1}$, sobre todo en verano y con un $18 \%$ de la precipitación total anual en invierno. Otra posibilidad, es que en la zona exista un proceso lento, pero consistente, de degradación generalizada de las comunidades vegetales, por actividades humanas como el sobre-pastoreo ganadero o la extracción de leña. En tal caso, la degradación consecuente de la vegetación afectaría a atributos ecosistémicos como la eficiencia de uso de la lluvia, un indicador que denota la capacidad de producción de biomasa vegetal de los ecosistemas en presencia de precipitación (Le Houerou, 1984; Pueyo, 2013), que se vincula estrechamente con la integridad ecológica y grado de conservación de las comunidades vegetales (Bai et al., 2008). Si la eficiencia en el uso de la lluvia disminuye, los ecosistemas no responden frente a la precipitación, y esto se refleja en una tendencia de no cambio en un indicador como el NDVI.

En particular sobre la posibilidad anterior, en estudios sobre áreas más pequeñas, se han obtenido tendencias temporales similares de los valores medios del NDVI sobre la vegetación, pero se ha incluido el impacto humano como una de los factores explicativos. Por ejemplo, Fuller (1998) analizó siete años de valores medios del NDVI para Senegal, durante el periodo 1987-1993, observando diferencias espaciales en las tendencias temporales del NDVI en función de las prácticas agrícolas y de manejo de pastizales. Pelkey et al. (2000) indicaron que, en Tanzania, la creación de áreas naturales protegidas favoreció el crecimiento de la cubierta vegetal y de biomasa en zonas que tenían un uso más intensivo. La presencia de una tendencia residual en los valores del NDVI después de haberle quitado la influencia climática suele considerarse una prueba de que otros factores, como el aprovechamiento humano de la tierra, están afectando a la actividad vegetal. En el presente estudio se han identificado tendencias significativas a la baja en las categorías suelo desnudo. Dada la alta intensidad de uso del suelo en la región, la atribución de estas tendencias en el NDVI es fácilmente atribuible a causa de la actividad humana en los piedemonte del área de estudio.

\subsection{Influencia de los factores topográficos y la distribución espacial de las tendencias temporales del NDVI (1986-2011) sobre las áreas vegetadas}

La tendencia temporal negativa del NDVI en la categoría de suelo desnudo no pudo ser explicada por los factores climáticos, aspecto que sugiere la presencia de procesos de degradación en algunos sectores del área de estudio. Esta posibilidad motivó una evaluación detallada de la distribución espacial de las tendencias temporales del NDVI para determinar la presencia de zonas de degradación.

La distribución espacial de las tendencias negativas y positivas del NDVI en las áreas vegetadas se muestra en la Fig. 7. Se observan grandes áreas donde las tendencias temporales fueron positivas, las cuales fueron explicadas por los factores climáticos (ver 
apartado 4.3), sin embargo, se puede apreciar áreas donde las tendencias fueron negativas, las cuales se pueden asociar a procesos de degradación de la cubierta vegetal. Por otra parte, las áreas con tendencia nula (estable) del NDVI, son áreas que por su estado de degradación no han sido capaces de mostrar actividad vegetal en las últimas décadas (1986-2011).

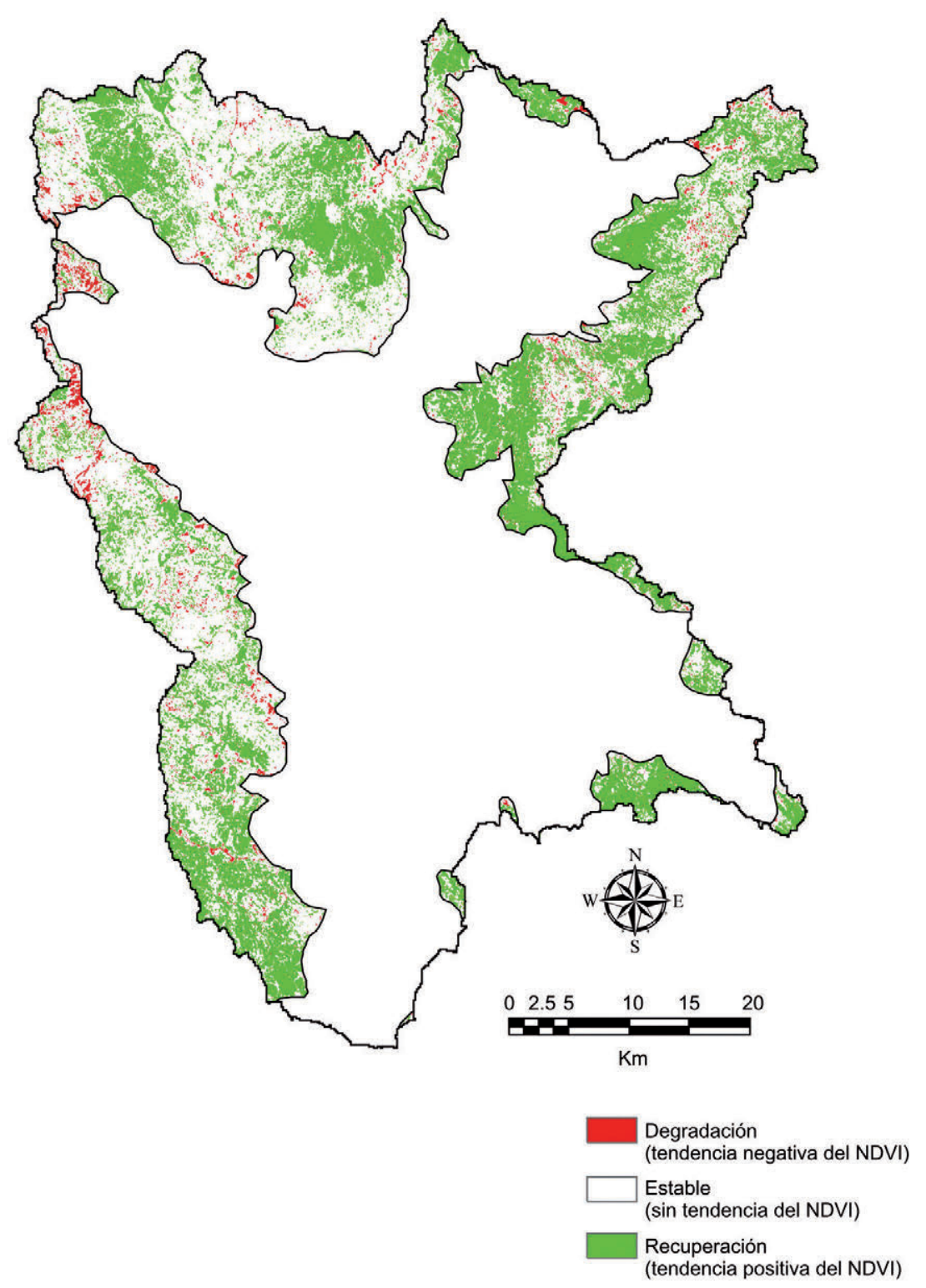

Figura 7. Distribución espacial de las tendencias temporales del NDVI (1986-2011) sobre las áreas vegetadas. 
La asignación de las tendencias temporales del NDVI píxel a píxel permitió evaluar en cada una de las categorías de coberturas y uso de suelo la ocurrencia de los proceso de recuperación y degradación de la cubierta vegetal (Fig. 8). En general, se observa que las tendencias positivas del NDVI tuvieron presencia en todas las categorías analizadas. Estos resultados confirman que la categoría de bosque de coníferas presentó una mayor recuperación, para seguir en orden descendente con las categorías de matorral, pastizales con matorral disperso y finalmente el suelo desnudo. Por otra parte, las tendencias negativas también estuvieron presentes en todas las categorías, pero fueron más evidentes en la categoría de suelo desnudo, afectando a un $18 \%$ de la misma.

Bosque de pino

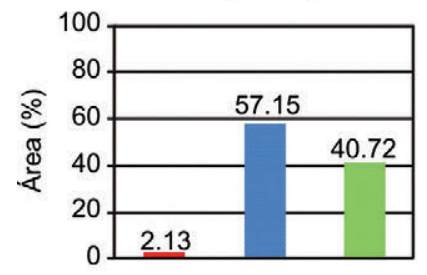

Suelo Desnudo

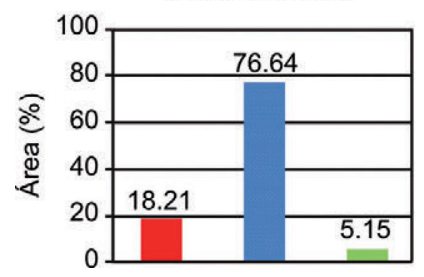

Pastizal con matorral

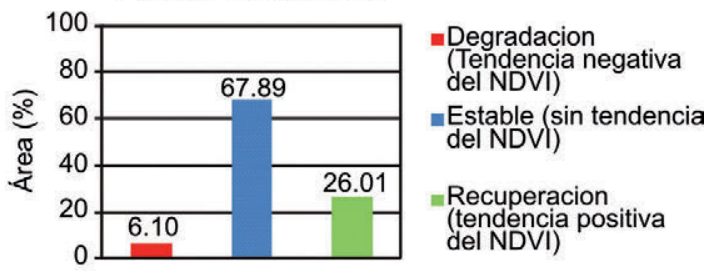

Matorral

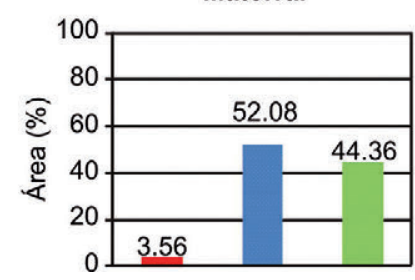

Figura 8. Análisis de la frecuencia (histograma) de las tendencias temporales del NDVI sobre las distintas categorías de vegetación presentes en las zonas serranas y piedemonte.

Finalmente, mediante el mapa de distribución espacial de las tendencias temporales de NDVI (Fig. 7), se analizó el grado de control que ejercen las variables topográficas sobre las tendencias temporales del NDVI (Fig. 9). La distribución de frecuencias en base a la pendiente topográfica $\left({ }^{\circ}\right)$ muestra claramente cómo los procesos de degradación son más acentuados en las pendientes menores a $10^{\circ}$, y los procesos de recuperación empiezan a ser más significativos conforme se va aumentando el grado de inclinación. En cuanto a la orientación de las laderas se observan procesos de degradación en las zonas con escasa insolación durante el año (Noreste y Este), y los procesos de recuperación tienen mayor presencia en las laderas con orientación opuesta a las de degradación (Suroeste y Oeste). La disección vertical por su parte ayudó a establecer que los procesos de degradación tienen una mayor presencia en las zonas localizadas en los piedemonte, mientras que los procesos de recuperación se localizan principalmente en las zonas escarpadas de las montañas. 
A)

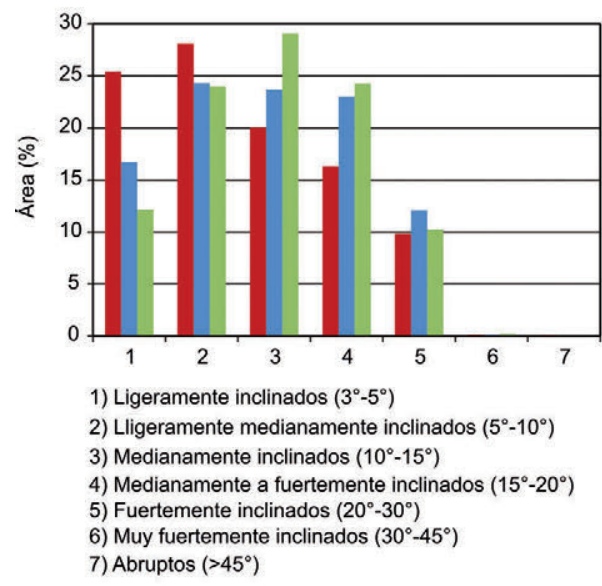

C)

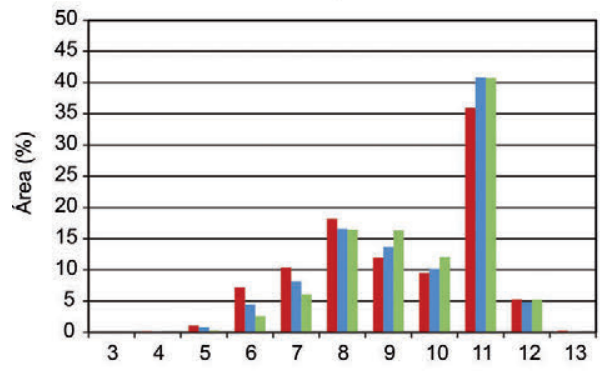

3) Planicies onduladas medianamente diseccionadas 4) Planicies onduladas fuertemente diseccionadas 5) Planicies acolinadas ligeramente diseccionadas 6) Planicies acolinadas medianamente diseccionadas 7) Planicies acolinadas fuertemente diseccionadas 8) Lomeríos ligeramente diseccionados
B)

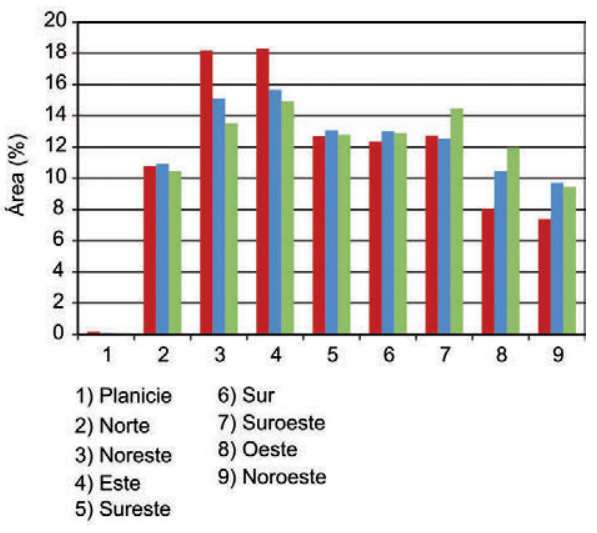

Figura 9. Análisis de frecuencia (histograma) de los procesos de recuperación y degradación vegetal en cada uno de los factores topográficos: A) pendiente $\left({ }^{\circ}\right)$; B) orientación de las laderas (aspecto); C) disección vertical.

Estos resultados demuestran que los procesos de degradación están más acentuados en las áreas de mayor accesibilidad (pendientes menores a $10^{\circ}$ ), lo cual se puede explicar por la explotación arbórea utilizada para producir leña que realizan principalmente los ejidos de la región (Fig. 1 F). Por otra parte, el hecho de que los procesos de degradación tengan una mayor presencia en las laderas con poca insolación y la recuperación en laderas con mayor insolación está en línea con otros estudios (Lasanta et al., 2000; Vicente-Serrano et al., 2004; Lasanta y Vicente-Serrano, 2006; Pueyo y Beguería, 2007). Finalmente, de acuerdo a la disección vertical los procesos de degradación ocurren con mayor frecuencia en los piedemonte, que se caracterizan por ser zonas de transición entre distintas ocupaciones del suelo y donde se realizan la mayoría de las actividades humanas. 


\section{Conclusiones}

El presente trabajo muestra la utilidad de las técnicas de teledetección y SIG en la investigación geoambiental básica y aplicada, a escalas de cuenca y regional (áreas de estudio entre los 10 y los $10000 \mathrm{~km}^{2}$ ). La utilización de técnicas de clasificación supervisada mediante el método de máxima verosimilitud a partir de un conjunto a priori de categorías (cubiertas), ha permitido obtener una cartografía de las coberturas y uso de suelo presentes en el área de estudio, con un nivel de fiabilidad del 84\%. Sin olvidar que la correcta selección de áreas de entrenamiento más la incorporación del NDVI ha permitido localizar áreas para cada una de las categorías (réplicas), dando como resultado una máxima variabilidad posible de las signaturas espectrales entre las mismas.

La serie homogenizada del NDVI de los meses de marzo-abril (inicios de primavera) permitió el análisis de la dinámica espacial y temporal de la actividad vegetal en áreas vegetadas (bosque de coníferas, matorrales y pastizales con matorral disperso) y en zonas degradadas (suelo desnudo) con escaza cobertura vegetal. Los resultados fueron espacialmente coherentes, y los patrones del NDVI fueron claros coincidiendo con la distribución espacial de las coberturas vegetales y usos de suelo. En resumen, este estudio demostró que, en una zona montañosa representativa de la región central de Chihuahua, México, se ha producido un aumento significativo en la actividad vegetal en los últimos 26 años, a inicios de primavera, lo que se explica en gran medida por la variación temporal que ha experimentado la temperatura mínima en el periodo de estudio (1986-2011). El bosque de coníferas y los matorrales son las categorías que han mostrado el mayor incremento en la actividad vegetal, mientras que el aumento de la actividad en los pastizales con matorral disperso ha sido moderado. Por otra parte, la erosión activa y las condiciones ambientales extremas, presentes en los suelos desnudos localizados principalmente en piedemonte, han restringido los procesos de recuperación de la vegetación durante este período de tiempo. Finalmente queda patente que la utilización de un MDT para hacer una exploración morfológica de la distribución espacial de las tendencias temporales del NDVI, procesos de recuperación y degradación vegetal, es una herramienta útil como primer acercamiento. La pendiente y la disección vetical, fueron los factores que mejor discriminaron los procesos de recuperación y degradación de la cubierta vegetal, demostrando que en el periodo de estudio la pérdida de vegetación ocurre con mayor frecuencia en las áreas con menor pendiente y en los piedemonte del área.

\section{Referencias bibliográficas}

Achard, F., Eva, H.D., Stibig, H.J., Mayaux, P., Gallego, J., Richards, T., Malingreau, J.P. 2002. Determination of the deforestation rates of the world's humid tropical forests. Science 297, 999-1002.

Alatorre, L.C., Beguería, S. 2009. Identification of eroded areas using remote sensing in a badlands landscape on marls in the central Spanish Pyrenees. Catena 76, 182-190.

Alatorre, L.C., Beguería, S., García-Ruiz, J.M. 2010. Regional scale modeling of hillslope sediment delivery: a case study in Barasona reservoir watershed (SPAIN) using WATEM/ SEDEM. Journal of Hydrology 391, 109-123. 
Alatorre, L.C., Beguería, S., Vicente-Serrano, S. 2011. Evolution of vegetation activity on vegetated, eroded, and erosion risk areas in the central Spanish Pyrenees, using multitemporal Landsat imagery. Earth Surface Processes and Landforms 36, 309-319.

Alatorre, L.C., Beguería, S., Lana-Renault, N., Navas, A. 2013. Modelización espacialmente distribuida de la erosión y el transporte de sedimento en cuencas de montaña del Pirineo aragonés: retos para la calibración y validación. Cuadernos de Investigación Geográfica 39 (2), 259-285.

Andreu, L., Gutiérrez, E., Macías, M., Ribas, M., Bosch, O., Camarero, J.J. 2007. Climate increases regional tree-growth variability in Iberian pine forests. Global Change Biology 13, 804-815.

Bai, Z. G., Dent, D.L., Olsson, L., Schaepman, M.E. 2008. Proxy global assessment of land degradation. Soil Use and Management 24(3), 223-234.

Beguería, S., López-Moreno, J.I., Lorente, A., Seeger, M., García-Ruiz, J.M. 2003. Assessing the effect of climate oscillations and land-use change on streamflow in the central Spanish Pyrenees. Ambio 32(4), 283-286.

Bravo, L.C., Díaz, R., Alatorre, L.C., Sánchez, E., Aguilar, S. 2012. Cambios de la cubierta vegetal y los usos del suelo en una cuenca endorreica de la región central de Chihuahua en el periodo 1993-2010. En Una zonificación desde la perspectiva hidrofuncional, J. Mas, G. Cuevas (eds.), Memorias de la XIX Reunión Nacional SELPER, Centro de Investigaciones en Geografía Ambiental, UNAM, pp. 390-398.

Bravo, L.C., Castellanos, A.E. 2013. Tendencias del Índice de la Diferencia Normalizada de la Vegetación (NDVI) en el estado de Sonora. Implicaciones potenciales sobre el sector pecuario en el contexto del cambio climático. En Dinámicas locales del cambio ambiental global. Aplicaciones de percepción remota y análisis espacial en la evaluación del territorio, E. Sánchez, R. Díaz (eds.), Universidad Autónoma de Ciudad Juárez, pp. 245-284.

Bryan, R., Yair, A. 1982. Perspectives on studies of badland geomorphology. En Badland Geomorphology and Piping, R. Bryan, A. Yair (eds.), Geobooks, Norwich, pp. 1-12.

Campbell, I.A. 1989. Badlands and badland gullies. En Arid Zone Geomorphology, D.S.G. Thomas (edr.), Belhaven, London, pp. 159-183.

Chavez, J. 1988. An improved dark-object subtraction technique for atmospheric scattering correction of multispectral data. Remote Sensing of Environment 24, 459-479.

CONAGUA 2010. Registro Público de Derechos de Agua, Comisión Nacional del Agua. Disponible en: www.conagua.gob.mx (Fecha de acceso: 15/10/2010).

CONAGUA 1991. Actualización del estudio geohidrológico, políticas de operación y proyecto de manejo del acuífero del Valle de Cuauhtémoc Chihuahua. Comisión Nacional del Agua, Contrato CNA-GRN-90-009, pp. 186.

DeFries, R., Houghton, R.A., Hansen, M.C., Field, C.B., Skole, D., Townshend, J. 2002. Carbon emissions from tropical deforestation and regrowth based on satellite observations for the 1980s and 1990s. Proceeding of the National Academic of Sciences of the United States of America 99, 14256-14261.

Delbart, N., Le Toan, T., Kergoat, L., Fedotova, V. 2006. Remote sensing of spring phenology in boreal regions: a free of snow-effect method using NOAA-AVHRR and SPOT-VGT data (1982-2004). Remote Sensing of Environment 101, 52-62.

Delbart, N., Picard, G., Le Toan, T., Kergoat, L., Quegan, S., Woodward, I., Dye, D., Fedotova, V. 2008. Spring phenology in boreal Eurasia in a nearly century time-scale. Global Change Biology 14 (3), 603-614.

Eastman 2004. IDRISI Kilimanjaro, Guía para SIG y Procesamiento de Imágenes. Clark Labs, Clark University, Worcester, MA, USA. 
Farrar, T.J., Nicholson, S.E., Lare, A.R. 1994. The influence of soil type on the relationships between NDVI, rainfall and soil moisture in semiarid Botswana II: NDVI response to soil moisture. Remote Sensing of Environment 50, 121-133.

Florinsky, I.V., Kuryakova, G.A. 1996. Influence of topography on some vegetation cover properties. Catena 27, 123-141.

Fuller, D.O. 1998. Trends in NDVI time series and their relation to rangeland and crop production in Senegal, 1987-1993. International Journal of Remote Sensing 19, 2013-2018.

Franklin, K.A., Lyons, K., Nagler, P.L., Lampkin, D., Glenn, E.P., Molina-Freaner, F., Huete, A.R. 2006. Buffelgrass (Pennisetum ciliare) land conversion and productivity in the plains of Sonora. Biological Conservation 127 (1), 62-71.

Gallart, F., Llorens, P., Latron, J., Regüés, D. 2002. Hydrological processes and their seasonal controls in a small Mediterranean -mountain catchment in the Pyrenees. Hydrology and Earth System Sciences 6 (3), 527-537.

Giglio, L., Csiszar, I., Justice, C.O. 2006. Global distribution and seasonality of active fi res as observed with the Terra and Aqua Moderate Resolution Imaging Spectroradiometer (MODIS) sensors. Journal of Geophysical Research 111, G02016.

Gutman, G., Tarpley, D., Ignatov, A., Olson, S. 1995. The enhanced NOAA global land dataset from the advanced very high resolution radiometer. Bulletin of the American Meteorological Society 76, 1141-1156.

Hill, J., Stellmes, M., Udelhoven, T., Röder, A., Sommer, S. 2008. Mediterranean desertification and land degradation. Mapping related land use change syndromes based on satellite observations. Global and Planetary Change 64, 146-157.

Kawabata, A., Ichii, K., Yamaguchi, Y. 2001. Global monitoring of interannual changes in vegetation activities using NDVI and its relationships to temperature and precipitation. International Journal of Remote Sensing 22, 1377-1382.

Lasanta, T., Vicente-Serrano, S., Cuadrat, J.M. 2000. Marginación productiva y recuperación de la cubierta vegetal en el Pirineo: un caso de estudio en el Valle de Borau. Boletín de la Asociación de Geógrafos Españoles 29, 5-28.

Lasanta, T., Vicente-Serrano, S. 2006. Factores en la variabilidad espacial de los cambios en la cubierta vegetal en el Pirineo. Cuadernos de Investigación Geográfica 32, 57-80.

Lasanta, T., Vicente-Serrano, S. 2007. Cambios en la cubierta vegetal en el Pirineo Aragonés en los últimos 50 años. Pirineos 162, 125-154.

Lasanta, T., Vicente-Serrano, S.M. 2012. Complex land cover change processes in semiarid Mediterranean regions: an approach using Landsat images in northeast Spain. Remote Sensing of Environment 124, 1-14.

Le Houerou, H.N. 1984. Rain use efficiency: a unifying concept in arid-land ecology, Journal of Arid Environments 7, 213-247.

Lucht, W., Prentice, I.C., Myneni, R.B., Sitch, S., Friedlingstein, P., Cramer, W., Bousquet, P., Buermann, W., Smith, B. 2002. Climatic control of the high-latitude vegetation greening trend and Pinatubo effect. Science 296, 1687-1689.

Martínez-Villalta, J., López, B.C., Adell, N., Badiella, L., Ninyerola, M. 2008. Twentieth century increase of Scots pine radial growth in NE Spain shows strong climate interactions. Global Change Biology 14 (12), 2868-2881.

Maselli, F. 2004. Monitoring forest conditions in a protected Mediterranean coastal area by the analysis of multiyear NDVI data. Remote Sensing of Environment 89, 423-433.

Morgan, P.C. 1997. Erosión y conservación del suelo. Mundi-Prensa, Madrid, 343 pp.

Myneni, R.B., Tucker, C.J., Asrar, G., Keeling, C.D. 1998. Interannual variations in satellitesensed vegetation index data from 1981 to 1991. Journal of Geophysical Research 103 (6), 6145-6160. 
Nadal-Romero, E., Regüés, D., Martí-Bono, C., Serrano-Muela, P. 2007. Badlands dynamics in the Central Pyrenees: temporal and spatial patterns of weathering processes. Earth Surfaces Processes and Landforms 32 (6), 888-904.

Olsson, E.G.A., Austrheim, G., Grenne, S.N. 2000. Landscape change patterns in mountains, land use and environmental diversity, Mid- Norway 1960-1993. Landscape Ecology 15, 155-177.

Palá, V., Pons, X. 1996. Incorporation of relief in polynomial-based geometric corrections. Photogramm. Eng. Remote Sensing 61, 935-944.

Pardini, G. 1996. Evoluzione temporale della microtopografia superficiale, della micromorfologia $e$ della struttura in relazione ai processi di meteorizzazione nelle marne smectitiche di Vallcebre. Ph.D. Dissertation, Universidad de Barcelona, Barcelona.

Pelkey, N.W., Stoner, C.J., Caro, T.M. 2000. Vegetation in Tanzania: assessing long term trends and effects of protection using satellite imaginery. Biological Conservation 94, 297-309.

Priego, AG., Bocco G., Mendoza M., Garrido, A. 2010. Propuesta para la generación semiautomatizada de unidades de paisajes. Serie Planeación Territorial, Centro de Investigaciones en Geografía Ambiental, UNAM, Morelia, México, 104 pp.

Pueyo, Y. 2013. Aportación de los modelos ecohidrológicos con feedbacks al conocimiento del funcionamiento de los ecosistemas de zonas áridas y semi-áridas. Cuadernos de Investigación Geográfica 39 (2), 243-258.

Pueyo, Y., Beguería, S. 2007. Modelling the rate of secondary succession after farmland abandonment in a Mediterranean mountain area. Landscape and Urban Planning 83 (4), 245-254.

Regüés, D. 1995. Meteorización física en relación con los procesos de producción y transporte de sedimentos en un área acarcavada. Tesis Doctoral inédita, Universidad de Barcelona, Barcelona.

Regüés, D., Pardini, G., Gallart, F. 1995. Regolith behaviour and physical weathering of clayey mudrock as dependent on seasonal weather conditions in a badland area at Vallcebre, Eastern Pyrenees. Catena 25 (1-4), 199-212.

Riaño, D., Chuvieco, E., Salas, J., Aguado, I. 2003. Assessment of different topographic corrections in Landsat TM data for mapping vegetation types. IEEE Transactions on Geoscience and Remote Sensing 41 (5), 1056-1061.

Riaño, D., Ruiz, J.A.M., Isidoro, D., Ustin, S.L. 2007. Global spatial patterns and temporal trends of burned area between 1981 and 2000 using NOAA-NASA Pathfinder. Global Change Biology 13, 40-50.

Romo, J.R. 2006. Conservation and the changing pattern of land cover and land use in central Sonora Mexico. En Environmental sciences and policy, Northern Arizona University, Flagstaff, AZ, 103 pp.

Rouse, J.W., Hass, R.H., Schell, J.A., Deering, D.W., Harlan, J.C. 1974. Monitoring the Vernal Advancement and Retrogradation (Greenwave Effect) of Natural Vegetation. NASA/GSFC type III final report, NASA/GSFC, Greenbelt, MD.

Ruimy, A., Sangier, B., Dediu, G. 1994. Methodology for the estimation of terrestrial primary production from remotely sensed data. Journal of Geophysical Research 99 (3), 5263-5283.

Salinas-Zavala, C., Douglas, A., Díaz, H. 2002. Interannual variability of NDVI in northwest Mexico. Associated climatic mechanisms and ecological implications. Remote Sensing of Environment 82 (2-3), 417-430.

Sarris, D., Christodoulakis, D., Körner, C. 2007. Recent decline in precipitation and tree growth in the eastern Mediterranean. Global Change Biology 13, 1187-1200.

Sellers, PJ. 1985. Canopy reflectance, photosynthesis and transpiration. International Journal of Remote Sensing 6, 1335-1372. 
Slayback, D., Pinzon, J., Los, S., Tucker, C. 2003. Northern hemisphere photosynthetic trends 1982-1999. Global Change Biology 9, 1-15.

Sluiter, R., De Jong, S.M. 2007. Spatial patterns of Mediterranean land abandonment and related land cover transitions. Landscape Ecology 22, 559-576.

Stohlgren, T.J., Chase, T.N., Pielke, R.A., Kittel, T.G.F., Baron, J.S. 1998. Evidence that local land use practices influence regional climate, vegetation and stream flow patterns in adjacent natural areas. Global Change Biology 4, 495-504.

Torri, D., Rodolfi, G. 2000. Badlands in changing environments: an introduction. Catena 40, 119125.

Tucker, C.J. 1979. Red and photographic infrared linear combination for monitoring vegetation. Remote Sensing of Environment 8(2), 127-150.

Tucker, C.J., Holben, B.N., Elgin, J.H., McMurtrey, J.E. 1981. Remote sensing of total dry matter accumulation in winter wheat. Remote Sensing of Environment 11, 171-189.

Tucker, C.J., Sellers, P. 1986. Satellite remote sensing of primary production. International Journal of Remote Sensing 7, 1395-1416.

Venables, W.N., Ripley, B.D. 2002. Modern Applied Statistics with S. Springer, New York.

Vermote, E.F., Tanré, D., Deuzé, J.L., Herman, M., Morcrette, J.J. 1997. Second simulation of the satellite signal in the solar spectrum, 6s: An overview. IEEE Trans. Geosci. Remote Sens. 35, 675-686.

Vicente-Serrano, S.M., Lasanta, T., Romo, A. 2004. Analysis of the spatial and temporal evolution of vegetation cover in the Spanish central Pyrenees: the role of human management. Environmental Management 34, 802-818.

Vicente-Serrano, S., Beguería, S., Lasanta, T. 2006a. Diversidad espacial de la actividad vegetal en campos abandonados del Pirineo español: Análisis de los procesos de sucesión mediante imágenes Landsat (1984-2001). Pirineos 161, 59-84.

Vicente-Serrano, S.M., Cuadrat-Prats, J.M., Romo, A. 2006b. Aridity influence on vegetation patterns in the middle Ebro Valley (Spain): evaluation by means of AVHRR images and climate interpolation techniques. Journal of Arid Environments 66, 353-375.

Vicente-Serrano, S.M., Zouber, A., Lasanta, T., Pueyo, Y. 2012. Dryness is accelerating degradation of vulnerable shrublands in semiarid Mediterranean environments. Ecological Monographs $82,407-428$.

Zeng, J., Neelin, D., Lan, K.M., Tucker, C.J. 1999. Enhancement of interdecadal climate variability in the Sahel by vegetation interaction. Science 286, 1537-1540. 